\title{
Educational attainment, labour market conditions and the timing of first and higher-order births in Britain
}

\author{
Andrew Jenkins \\ Institute of Education, University of London \\ a.jenkins@ioe.ac.uk
}

(Received December 2010 Revised March 2011)

\begin{abstract}
This paper presents analyses of the effects of women's education and the rate of aggregate unemployment on birth hazards using data from the 1958 and 1970 British cohort studies. The hazard of first birth was negatively associated with higher levels of education. Once controls for unobservables were included, there was no relationship between education and the hazard of second births. Lagged unemployment was found to be negatively related to first birth hazards but this was only statistically significant among the later cohort, while for higher order births there was evidence of a positive association with unemployment.
\end{abstract}

\section{Introduction}

This paper analyses fertility in Britain, with special reference to the effects of women's education and the state of the labour market. The research uses longitudinal micro-data on two cohorts who had different experience of education, combined with macro-data on labour market conditions to examine how these factors impacted on the timing of births. Hazard models were estimated separately for each of the two cohorts. The models analyse the timing of the first three births, focusing on the associations of birth hazards with education level and a time-varying unemployment covariate.

The research develops the literature on this topic in several important ways. Both first births and higher-order births will be considered. Much of the literature has looked just at the timing of the first birth, which gives a very incomplete picture of fertility as a whole. Secondly, many published papers do not allow for unobserved heterogeneity. This is vital as there may, for example, be unobserved characteristics of women which drive their decisions about both education and fertility. Controlling for such heterogeneity in the sample is then crucial in order to attempt to make inferences about causation rather than just associations among the variables, and our estimates use techniques which allow us to control robustly for unobserved heterogeneity. Thirdly, I use rich data on two cohorts of women which allow a full range of relevant controls, including factors from the childhood of the cohort members, to be incorporated into the model.

\section{Literature Review}

In Britain, as in other developed economies, successive cohorts have tended to wait longer before starting a family. The stylized facts are that, among women born in England and Wales in the 1950s, fewer than a quarter were still childless by age 30 , but for women born in the early 1970s, about 40 per cent were still childless by the time they reached 30 . In earlier cohorts, too, a higher proportion of women became mothers by the end of their reproductive lives. Around 13 per cent of women born in 1950 remained childless. This rose to 18 per cent of women born in 1960 and it is estimated that about the same proportion of those born in 1970 will not have 
children (ONS 2007; Bray 2008). The statistical association between education and the timing of first births is quite well-established. What is less clear is the more difficult question of whether education can be said to have any causal link with birth hazards; the evidence on the direction of the relationship between education and higher-order births has also proved more mixed than that for first births.

Education of women is widely regarded as a central factor in the trend to fewer and later births in developed economies. A higher level of education is associated with beginning child-bearing at a later age and with fewer children, on average, by the end of a woman's reproductive years. This can be explained very broadly in terms of the greater opportunity cost of forgone earnings, which will be higher for welleducated women who have greater earning power. This would be a rationale for avoiding childbearing while still studying, as well as for deferring, if not avoiding, it once on the labour market (e.g. Hotz et al 1997). However, education increases income, through own earnings and possibly through assortative mating, which could have a positive effect on fertility, reducing or outweighing the substitution effect, especially at later ages and stages in the reproductive span (Gustaffson 2001). In particular, higher earning power may make it easier to afford the costs of reducing forgone earnings through the purchase of childcare (Ermisch 1989) and of owner-occupied housing. Another route which connects low education to early and extended childbearing, is that women who are (or will be) better educated, are better equipped to avoid unintended births.

It is well-established in the demographic literature, that a higher level of education is associated with later timing of the first birth (e.g. Gustafsson 2001). The relationship between educational attainment and transition rates to higher order births remains less clear. The empirical evidence is mixed but several studies have reported that women with higher levels of education have made more rapid transitions to second and/or third births. Kravdal (1992) found a positive association between education and third births for Norway, while Kreyenfeld (2002) reported a similar association for second births in Germany. For Britain, Wright et al (1988), using data from the 1980 Women and
Employment Survey, found no evidence that education exerted any influence on progression to third births.

More recently, Rendall and Smallwood (2003) examined parity progression by education level, using data from the Office for National Statistics (ONS) Longitudinal Study for women born between 1954 and 1958. They presented descriptive findings rather than model-based analyses but the results are, nonetheless, interesting. Average age of entry to motherhood was some five years later for highly qualified women but, for any given age at birth of first child, highly qualified women were relatively more likely to have another child and tended to do so more quickly than less well educated mothers. Aassve et al (2006) use data from the British Household Panel Study (BHPS) and estimate a sophisticated model with simultaneous hazards for births, union formation and dissolution, employment and non-employment events, in the presence of unobserved heterogeneity. On fertility, they find a negative relationship between education and the birth hazard (constrained to apply equally to each order). As the authors acknowledge, the complexity of their approach is bought at some cost in terms of the specification of each individual process; notably their specification does not allow for different processes for each birth i.e. the effect of education is assumed the same for each birth. In summary, then, there is overwhelming evidence that better educated women delay entry into motherhood. Some research has found that, once they begin childbearing, well-educated women proceed relatively quickly to second and higher-order births.

Cohorts reaching adulthood since the early 1970s have also experienced a labour market in which unemployment rates have been at times exceptionally high and in general, volatile. This applies both in Britain and in many other European economies. In the case of Britain, unemployment in the 1980s and early 1990s reached levels which had only previously been observed in the depressed decade of the 1930s (Crafts 2007). After the mid1990s, unemployment fell back to much lower levels. High unemployment might either deter or promote births, depending on whether the income effect of not being able to afford a(nother) child, dominates 
the substitution effect of the reduction in the mother's earning opportunity costs.

A number of papers have considered the relationship between unemployment and fertility. Ahn and Mira (2001) analyse the relationship between fertility and aggregate unemployment in Spain in the 1970s and 1980s. The Spanish (male) unemployment rate was below 5 per cent in the mid1970s, but climbed to around 20 per cent in the 1980s. The authors find that unemployment increased the average age at marriage. This higher age at marriage also reduced fertility (they consider the timing of the first three births) although the estimated effects of joblessness on birth hazards conditional on marriage were not statistically significant. Gutierrez-Domenech (2002) applied Cox hazard regression models to the timing of marriage and of births amongst two cohorts of Spanish women. The lagged unemployment rate was negatively and significantly related to the transition into marriage in both cohorts. The birth hazard models were fitted separately for each of the first three births and it was found that, after controlling for other factors, lagged unemployment was negatively associated with the hazard of each birth. This relationship was statistically significant for the first two births to the later cohort (born 1961-77) but was never significant for the earlier cohort (born 1945-60). Kreyenfeld (2000) used data from the German Socio-Economic Panel to study the relationship between unemployment and fertility in the former East Germany following unification. She focused on individual-level unemployment, i.e. whether the woman was herself unemployed at the time of conception, rather than the effect of aggregate unemployment. In a piecewise constant hazard model of first births, it was found that unemployed women were more likely to conceive. The model included age and education level as controls, and the positive association with unemployment applied only to women educated below degree level and not to those with degrees. Del Bono (2001) explored whether unemployment affects fertility through its influence on expectations of the future condition of the labour market. This study used data on a single cohort of young British women, observed up to age 33. It was shown that more favourable expected job opportunities raised the hazard of the first birth.
Studies of this topic for Scandinavian countries include Hoem (2000), who used data on Swedish women born in 1950 or later to analyse times to first birth in the 1980s and 1990s. It was found that the employment rate in the women's local municipality was positively associated with time to first birth in hazard regression models. Hoem used register data and so had few controls for the women's family background. Santow and Bracher (2001) drew on data from the 1992 Swedish Family Survey with a better range of controls, but obtained broadly similar results. They also applied hazard regression models to the time of conceptions leading to first birth. The age-specific unemployment rate was negatively related to the time of first birth conception. The estimated unemployment effects were quite substantial: relative to the base case of unemployment below four per cent, when unemployment was between four and nine per cent, first birth conception rates were reduced by a fifth, and when unemployment exceeded 10 per cent first birth conception rates were lowered by two-fifths. Santow and Bracher also report that their results were largely unaffected by lagging the unemployment variable by one or two years. Kravdal (2002) estimated hazard models separately for first and higher-order births based on Norwegian register data for the period 1992 to 1998. All unemployment variables were lagged by 12 months and included individual unemployment as well as both male and female unemployment rates at municipal level. The woman's own unemployment raised the hazard of the first birth 12 months later, but reduced the hazard of higher-order births. The municipal unemployment rates, both male and female, were associated with lower birth hazards for first and higher-order births. During the period studied, unemployment in Norway varied only between a minimum of two per cent and a maximum of six per cent and so was quite low compared to many other European economies.

Dex et al (2005) fitted Cox hazard regression models to cohort data on time to first birth in Britain, Sweden and the United States (US). Unemployment was measured as aggregate male unemployment rate. Higher unemployment was associated with a significantly lower hazard of motherhood in Sweden and the US but a significantly higher hazard in Britain. 
One of the notable features emerging from the literature review, is that studies of Scandinavian countries have tended to find a pro-cyclical relationship there with birth hazards. In good economic times, when unemployment is low, the birth hazard tends to increase. That is, the income effect appears to be out-weighing the substitution effect, and this, it may be conjectured, is related to the welfare state in Scandinavian countries, with generous support in cash and kind for those combining parenthood and employment, and low private opportunity costs of parenthood.

This review of the literature also suggests that most analyses of aggregate unemployment and fertility have tended to focus just on the first birth, and few papers have reported on higher order births. As for education and fertility, while many studies report negative associations between education and first birth, it is far from clear whether education has any causal impact or whether unobservable factors are determining both fertility and education levels of women.

\section{Research Questions and Method}

In a stylized economic model of fertility, abstracting from issues about partnership, it is usual to assume that having a child yields utility to the mother, but that there is also disutility from earnings lost (including the present value of lost future earnings) during time spent out of the labour force while bearing and looking after the young child. So the observed fertility and labour market behaviour of women will depend, in broad terms, on the strength of their preferences for children versus market work, and on the wages and employment opportunities available in the paid labour market (Dex et al 2005). In this framework, education could have a number of effects. Perhaps most important, acquiring more education raises the market wage, encouraging participation in paid work. On the other hand, education may increase home productivity too, thereby encouraging women to look after children in the home. There is also an income effect - higher earnings of educated women, especially lifetime earnings, make more children potentially affordable. So it is not possible to determine on the basis of theory alone, the direction in which education will influence fertility. From an empirical perspective a further key issue is whether an observed association between education level and fertility can be taken to be a causal effect, or whether it is in fact just reflecting heterogeneity in the population. For example, some women with a strong preference for high earnings and relatively little preference for children, may choose both to invest a lot of time in education and to have few, or no children; here education is not having any causal effect on their behaviour. It is vital, then, to make allowance for such heterogeneity when building good models.

For aggregate unemployment, as with education, while theory provides a useful framework for thought, it does not provide firm predictions about the direction of effects. Increases in aggregate unemployment may have a substitution effect, encouraging women to have children while prospects for paid work are poor. This is closely related to the 'discouraged worker' effect, where people drop out of the labour market during adverse times. Conversely, there is an income effect: in a recession it will become harder to earn sufficiently to afford children, so that women are encouraged to take jobs, work longer hours or anticipate that they may need to do so. This corresponds to the 'added worker' effect (for discussion of literature on added and discouraged workers, see e.g. Killingsworth and Heckman 1986). What is actually observed will depend on which of these effects - the discouraged or the added worker effect - is the stronger.

As noted in the literature review in countries such as Sweden, which have generous support for working mothers, birth hazards have a pro-cyclical pattern. In Britain, maternity leave arrangements and other support for working mothers has tended to become more generous over time (see the information in Appendix 1 for details). So it may be the case that more recent cohorts in Britain have exhibited a greater tendency to have pro-cyclical birth hazards than earlier cohorts. Since different cohorts do not experience the same labour market at the same age, it is not possible to test this formally, but it is of interest to consider whether the results which will emerge here are broadly consistent with such a pattern. 
So the research questions are, firstly, is there an association between education and the hazard of births? Secondly, to consider any differences between first and higher order births. Thirdly, the objective is to control for unobserved heterogeneity among the sample of women, enabling firmer inferences to be made about the causality of education'. Fourthly, what impact does aggregate unemployment have on fertility behaviour - does the added worker effect dominate the discouraged worker effect, or vice versa? And finally, as there are strong trends in the fertility behaviour of women in Britain, the research will consider two cohorts of women, 12 years apart, and determine whether or not the results differ between these two cohorts, after allowing for a range of observed predictors.

In terms of appropriate methods for the analysis, it is necessary to allow for the fact that not all women had a birth by the time they were most recently observed in the data. In other words, some women's birth histories were censored. Duration modelling is now well-established as the appropriate technique to deal with the analysis of times to an event in the presence of censoring (Allison 1984; Kiefer 1988). The basic insight is rather than focusing on factors directly affecting occurrence of the event, instead to look at factors which influence the risk of the event occurring (Newman and McCulloch 1984). Duration models were applied to the data on births. Here, interest centres on the probability that a person who has occupied a state for a certain length of time $t$ leaves it in the next short interval of time. Formally, the hazard is defined as:

$$
h(t)=\lim _{d t \rightarrow 0} \frac{P(t \leq T<t+d t \mid T \geq t)}{d t}
$$

The hazard of a birth at time $t$ given that it has not occurred prior to t will be estimated. Letting $f(t)$ be the probability density function and $S(t)=1-F(t)$ the survivor function, then the hazard function is also often written as:

$$
h(t)=\frac{f(t)}{S(t)}
$$

Duration models were estimated separately for each of the two cohorts on which I have data. An exponentiated quadratic was used as the functional form for the baseline hazard. This is preferable to other commonly used functional forms for the hazard, such as the Weibull model, as the quadratic allows for the possibility of a non-monotonic hazard, which is plausible when modelling the hazard for births. Explanatory variables in the model include education, unemployment as a time-varying covariate, and other factors, which economic theory and the empirical research literature suggest may be important, and which are described in more detail in the data section of the paper.

One of the advantages of longitudinal data is that it should be possible to control for omitted variables and unobservables much more effectively than when using cross-sectional data (Davies 1987). There has been considerable debate in the literature on duration models, on the best way to take account of unobservables. It is well known that neglecting to control for the presence of unobserved heterogeneity can lead to mis-specification of the baseline hazard, and that this could in turn bias the parameter estimates on explanatory variables (e.g. Blossfeld et al 2007). A widely-used method for taking account of unobservable factors is to assume a parametric distribution for the heterogeneity, and this distribution is usually chosen as some convenient functional form which will make the resulting mixing distribution analytically tractable (Lancaster 1990). Unfortunately, as Heckman and Singer (1984) note, empirical results can be sensitive to the functional form chosen for the parametric heterogeneity term. They proposed a non-parametric maximum likelihood procedure, in which the distribution of unobservables is approximated by a discrete distribution, and both the probability masses and their locations are estimated from the data. I also adopt this nonparametric approach and write the jth conditional hazard, $h_{j}$, for the jth birth as:-

$$
h_{j}=\exp \left\{\gamma_{0 j}+\gamma_{1 j} t_{j}+0.5 \gamma_{2 j} t^{2}{ }_{j}+Z \beta_{j}+f_{j} \theta\right\}
$$

where $t_{j}$ is the length of the jth spell; $Z$ is a vector of covariates, which may include time-varying covariates; $\theta$ is the person-specific unobserved heterogeneity component; and the $\gamma, \beta$, and $f$ terms are transition-specific parameters to be estimated. The first spell begins at age 16; subsequent spells 
begin at the time of previous birth plus nine months. All the estimations were carried out in the specialist statistical program for duration modelling, CTM (Continuous Time Models). The distribution of the unobservable term was estimated using the Heckman- Singer non-parametric maximum likelihood procedure. Here a one-factor structure is assumed, such that the unobservable for spell $j$ is $f_{j} \theta$ and the covariance between $f_{i} \theta$ and $f_{k} \theta$ is $f_{i} f_{k} \operatorname{Var}(\theta)$. By modelling the unobservables in this fashion, I allow for the unobserved heterogeneity to be correlated across spells. To obtain the estimates of the nonparametric distribution, I began by estimating the location and weights to be placed on just two mass points and continued to add mass points until two converge on the same location.

\section{Data}

The analyses of fertility use data from two British birth cohorts: the National Child Development Study (NCDS), a cohort of individuals all born in the same week in March 1958 and the British Cohort Study (BCS70), who were all born in a single week in April 1970. Members of each cohort have been surveyed at various points in their lives. For NCDS, detailed birth histories were collected in 1991 when cohort members were aged 33, in 2000, when they had reached the age of 42, and again in 2004 at the age of 46. For this project the data from the 2004 survey were combined with data from the 1991 and 2000 NCDS sweeps, making the fertility histories virtually complete. Data on birth histories for BCS70 were also collected in 2000 and 2004. Information from these two sweeps was joined together, taking the record up to age 34. Some women with incomplete birth history data were omitted from the quantitative analysis. The main omitted group was those NCDS women for whom information was only available on births which occurred from age 33, but not before that age. In other words, some left-censored cases were omitted. For both cohorts, cases where mothers had given birth to twins or triplets were also omitted. For NCDS, the sample used for analysis consists of 5,631 women and there are 5,105 BCS70 women in the analyses. For over three-quarters of the NCDS sample, there is a full birth history up to age 46, while for a further 15 per cent there is a history up to age 42 , and for the remaining nine per cent, a birth history which is truncated at age 33. For over four-fifths of the BCS sample, there is a full birth history up to age 34 , while for the remaining 17.5 per cent, a birth history which is truncated at age 29 or 30 .

\section{Explanatory variables}

Education is widely regarded as a key factor in understanding fertility behaviour and it was important to include it in the analysis. There are various ways of conceptualising education, each of which has some advantages and some disadvantages. Here, education attainment was treated as a fixed variable, based on years of completed education by age 30. Using a fixed covariate simplifies the specification and effectively treats the destination education level as if it were anticipated. An alternative would be to treat education as a timevarying covariate. In practice, relatively few women in the datasets substantially increased their years of completed education after their teens or early twenties. Our specification effectively rules out the possibility that low educational attainment is the result of early motherhood. There is evidence to support this. Studies of women who have children at a young age, suggest that early motherhood is a marker rather than a driver of subsequent disadvantage in the labour market. For example, Ermisch and Pevalin (2003, 2005) analysed the 1970 British birth cohort data and found that having a child as a teenager had little effect on a woman's qualifications, earnings and employment at age 30 . Hawkes' (2003) study on British twins, showed that the apparent effect of early motherhood on educational attainment was much smaller once antecedent factors had been controlled for. The conclusion from this is, that it is not unreasonable to treat women's education as a fixed covariate. For our analyses, education was categorised as low (11 years of completed education by age 30 ), medium (12 or 13 years of education) and high (more than 13 years of education). Leaving school at age 16 , the minimum school leaving age for both cohorts, would imply 11 years of education so the women in the low education category have no time spent in education beyond the minimum. Having 12 or 13 years of education would mean some secondary education beyond the minimum, but no tertiary education; 
those in the high education category have more than 13 years of education, so would usually have some tertiary education. Descriptive statistics on the education levels of women in the two cohorts are shown in Table 1. Among the NCDS women, over two-thirds were at low education level, approximately 17 per cent had medium education and 15 per cent had a high level of education. Larger proportions of BCS70 women were reported having education at the medium or high levels, reflecting the secular increase in enrolment and attainment (Makepeace et al 2003). Among the BCS70 cohort of women, about half were classified as low education, of the remainder, slightly more were in the medium education category than the high education category.

Table 1: Education Levels of the NCDS and BCS70 women

\begin{tabular}{lrrrr} 
Education Level & \multicolumn{2}{c}{ NCDS } & \multicolumn{2}{c}{ BCS70 } \\
& \multicolumn{2}{c}{1958 cohort } & \multicolumn{2}{c}{1970 cohort } \\
& $\mathrm{N}$ & $\%$ & $\mathrm{~N}$ & $\%$ \\
& & & & \\
& 3,831 & 68.0 & 2,572 & 50.4 \\
Low & 940 & 16.7 & 1,340 & 26.3 \\
Medium & 860 & 15.3 & 1,193 & 23.4 \\
High & & & & \\
TOTAL & 5,631 & 100.0 & 5,105 & 100.0
\end{tabular}

In Figures 1 to 4, Kaplan-Meier survival curves are plotted for the first two births among each cohort by education level, to illustrate how the timing of births differs for women with differing amounts of education. For the first birth, measured from age 16, Figure 1 and Figure 2 both show very clear differences in survival profiles by education level, with the highly educated taking longer to have a first child than those with a medium level of education, who in turn tend to take longer to begin child-bearing than those whose education level was categorised as low. Comparing Figure 1 and Figure 2, the earlier cohort, NCDS, tend to make the transition to motherhood at younger ages than those in the more recent cohort, BCS70. For the second birth, measured in months since first birth, there is some indication that women with high education make a more rapid transition to second birth although the survival curves for each level of education are very close together (Figures 3 and 4). 
Figure 1. Kaplan-Meier Survival Curve for First Birth by Education Level - NCDS

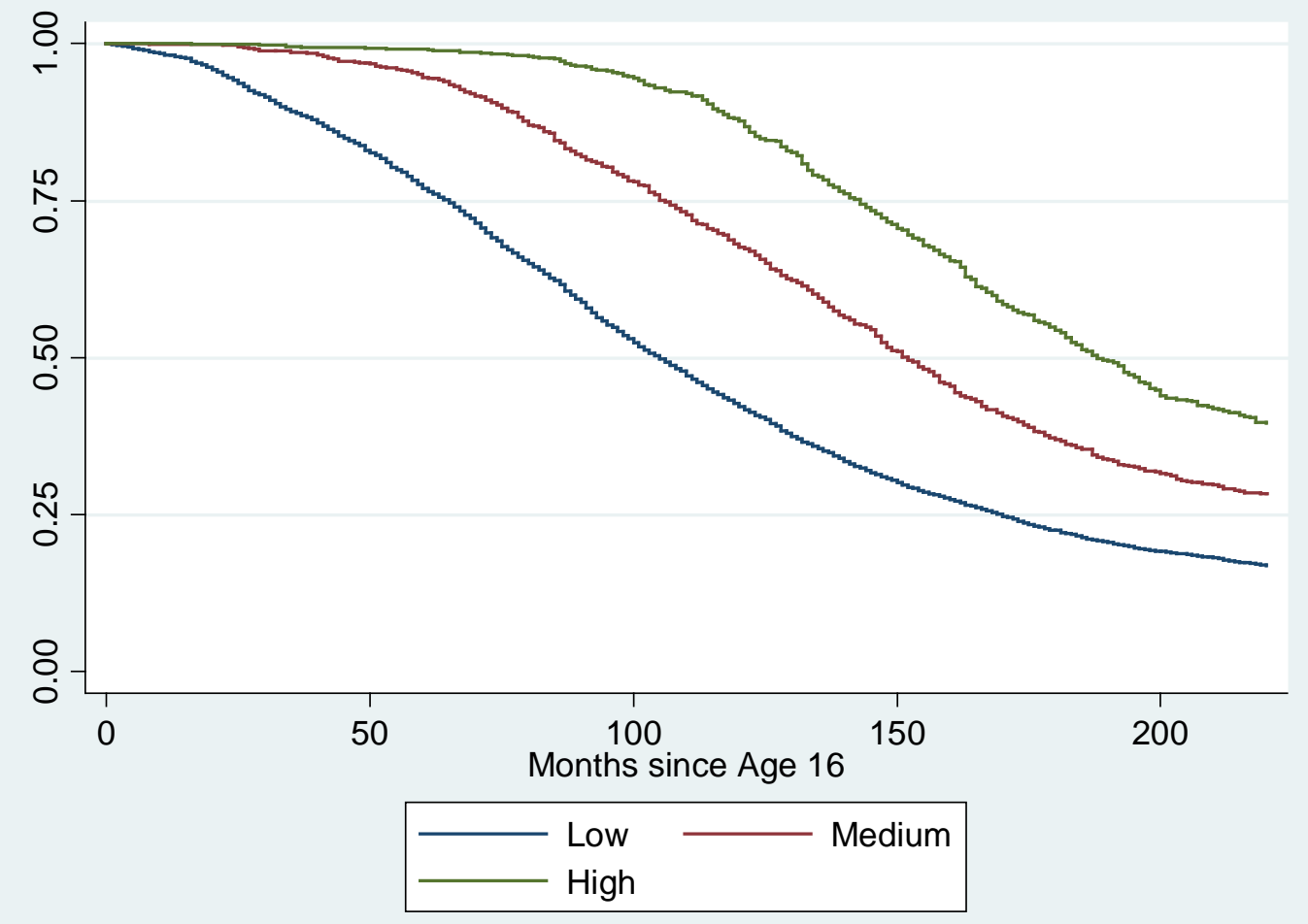

Figure 2. Kaplan-Meier Survival Curve for First Birth by Education Level BCS70

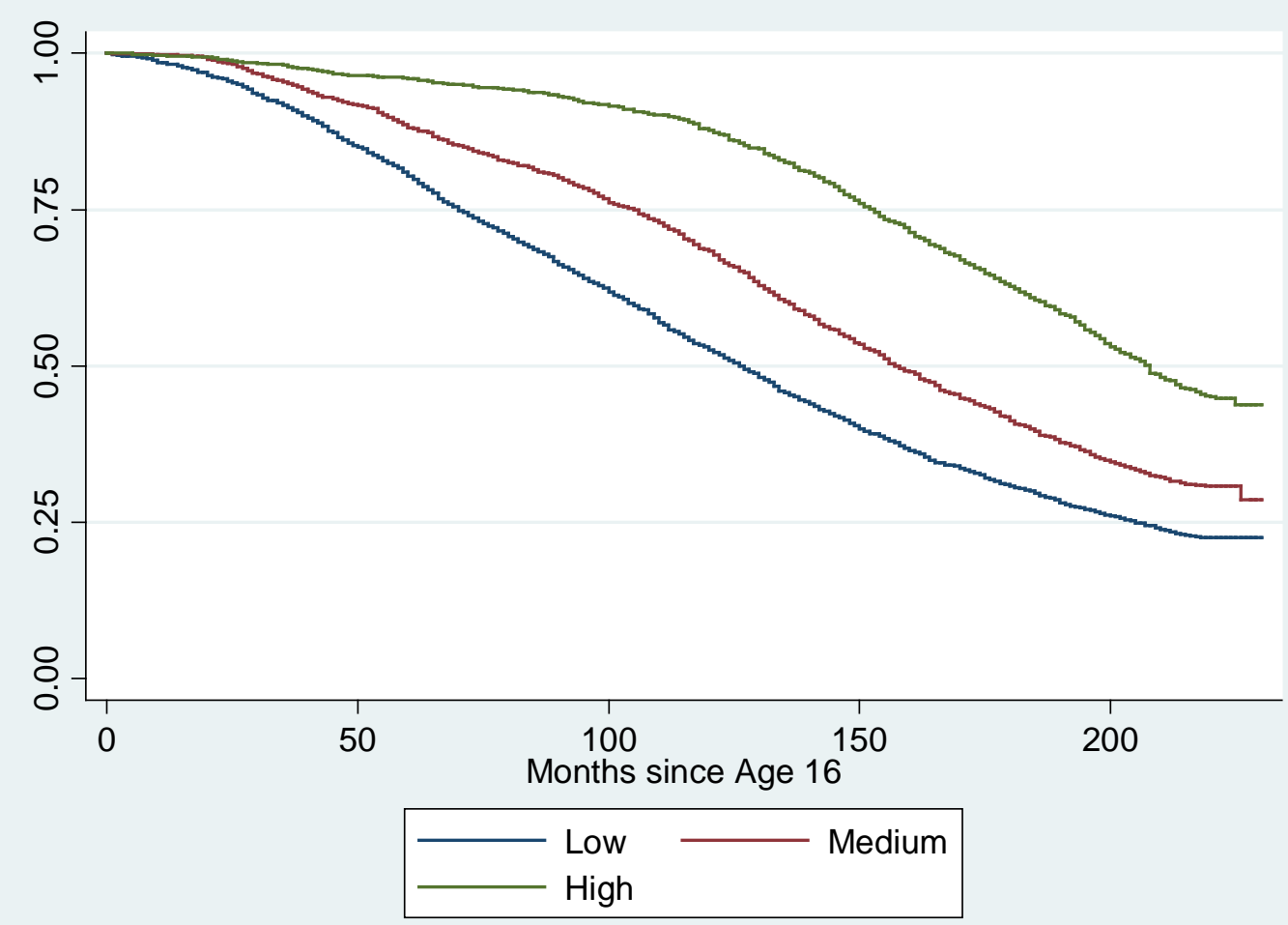


Figure 3. Kaplan-Meier Survival Curve for Second Birth by Education Level - NCDS

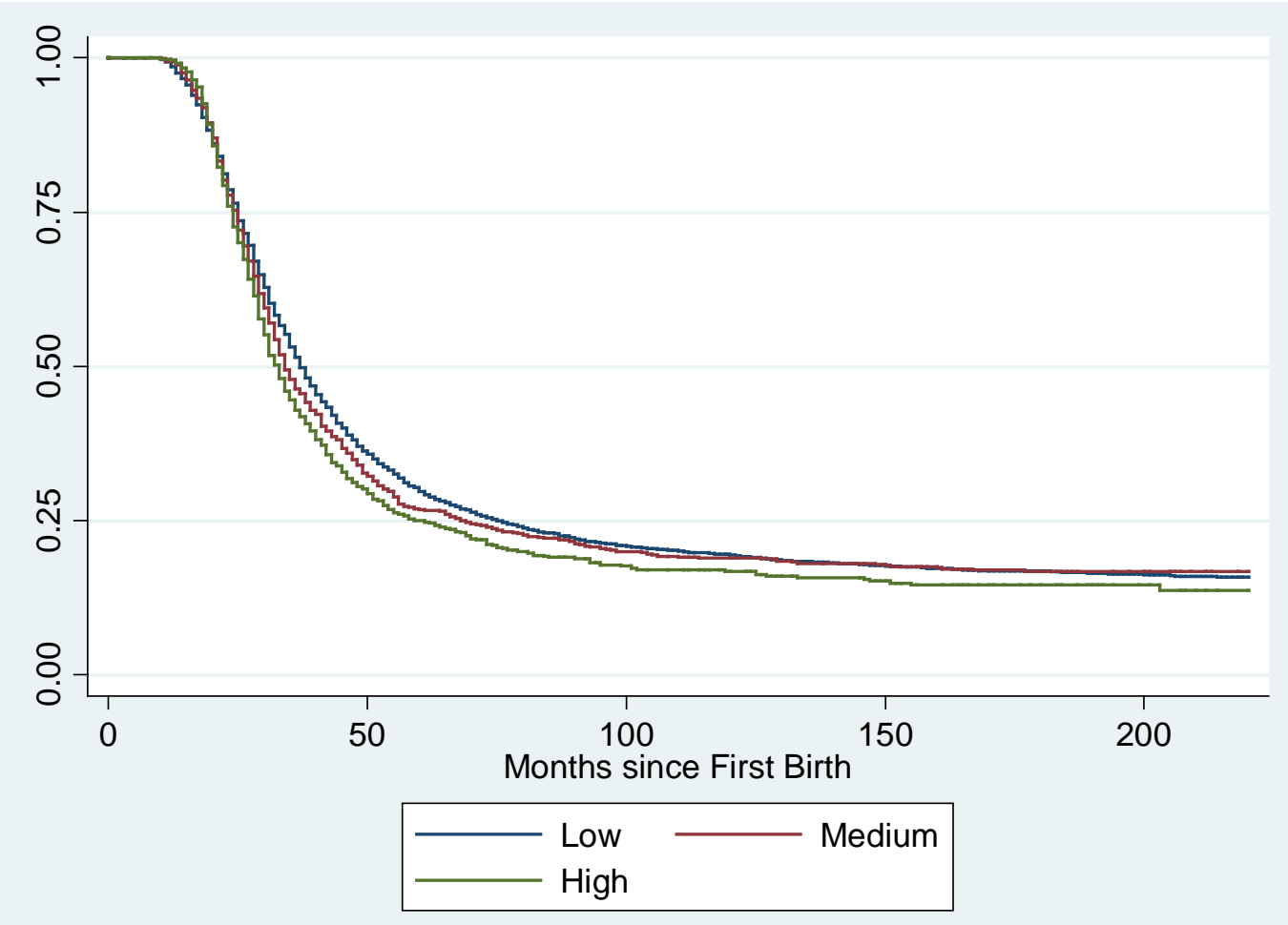

Figure 4. Kaplan-Meier Survival Curve for Second Birth by Education Level - BCS70

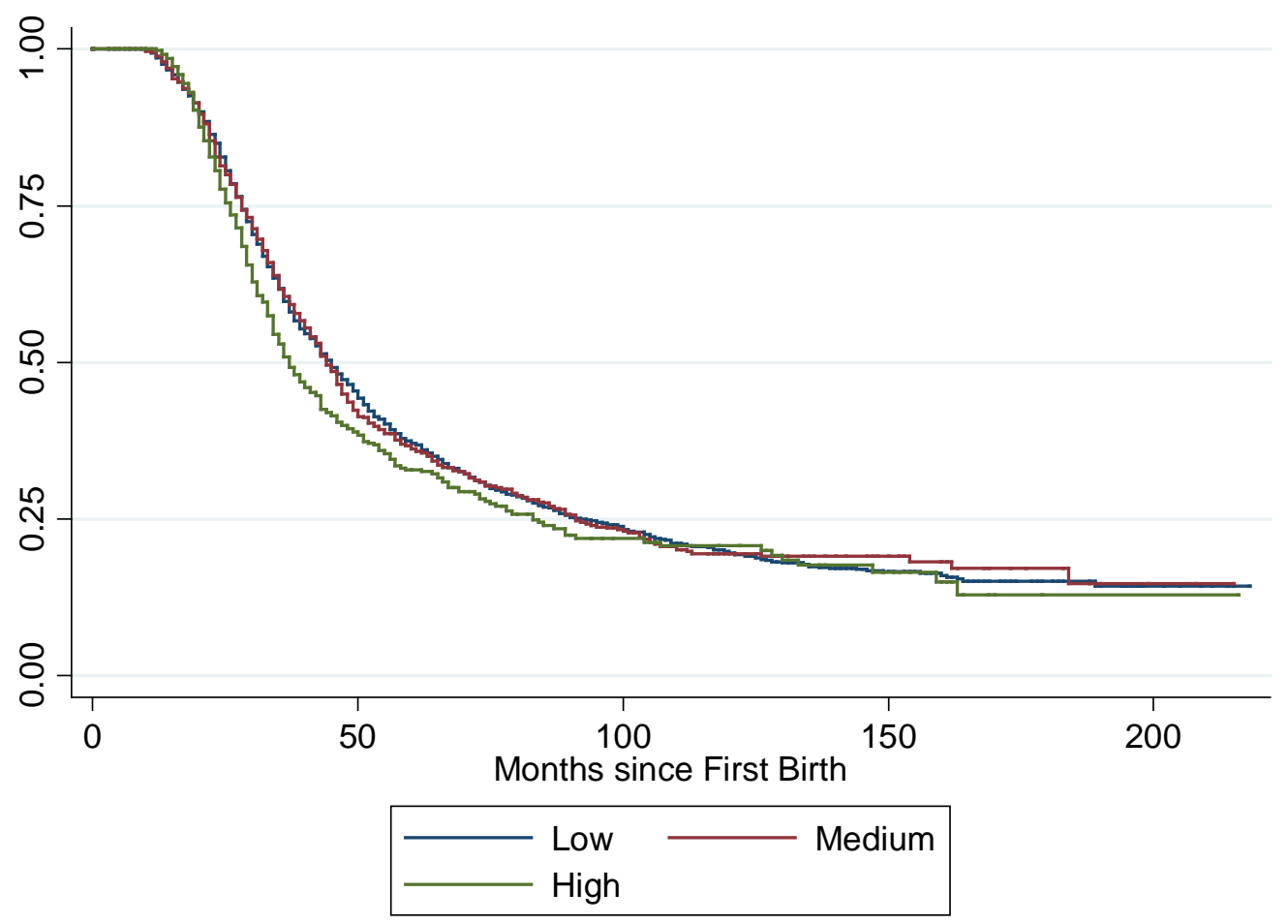


As a monthly series for births is being used, it is best to utilise a monthly series on unemployment, and here there were some tricky data issues, as for unemployment a monthly series is required which goes back to the early 1970s, when the 1958 cohort began to enter the labour market. The claimant count is the only series which meets this criterion. However, one serious problem with the claimant count is that it is affected by changes to the rules for eligibility to unemployment benefits. When unemployment was very high in the 1980s, several changes were made to the eligibility rules. I have therefore adjusted the claimant count with the aim of constructing a series which is consistent through time. Information from Lawlor (1990) was used on how many people were removed from the claimant count during the 1980 s by various rule changes, and these numbers were added back in to create an adjusted claimant count series. As in Boyer and Hatton (2002), minor changes - those which altered the claimant count by 20,000 or less - were not incorporated in the adjusted series.

I use the male claimant count rather than the female or all persons claimant count because additional long-term changes in women's eligibility to contribute towards unemployment benefits, mean that the adjusted series for male claimants is a better indicator of the state of the labour market than a series which includes female claimants. The impact of the eligibility changes for male unemployment rates is apparent in Figure 5. Unemployment rates were exceptionally high for much of the 1980s and again in the early 1990s. By the year 2000, the adjusted series was around 6 per cent approximately in line with estimates from the Labour Force Survey. The adjusted male claimant count, then, should give a more realistic picture of conditions in the labour market than the raw claimant count, and so it is the adjusted series which will be used in the analyses. 
Figure 5. Claimant Count Unemployment Rates - Males

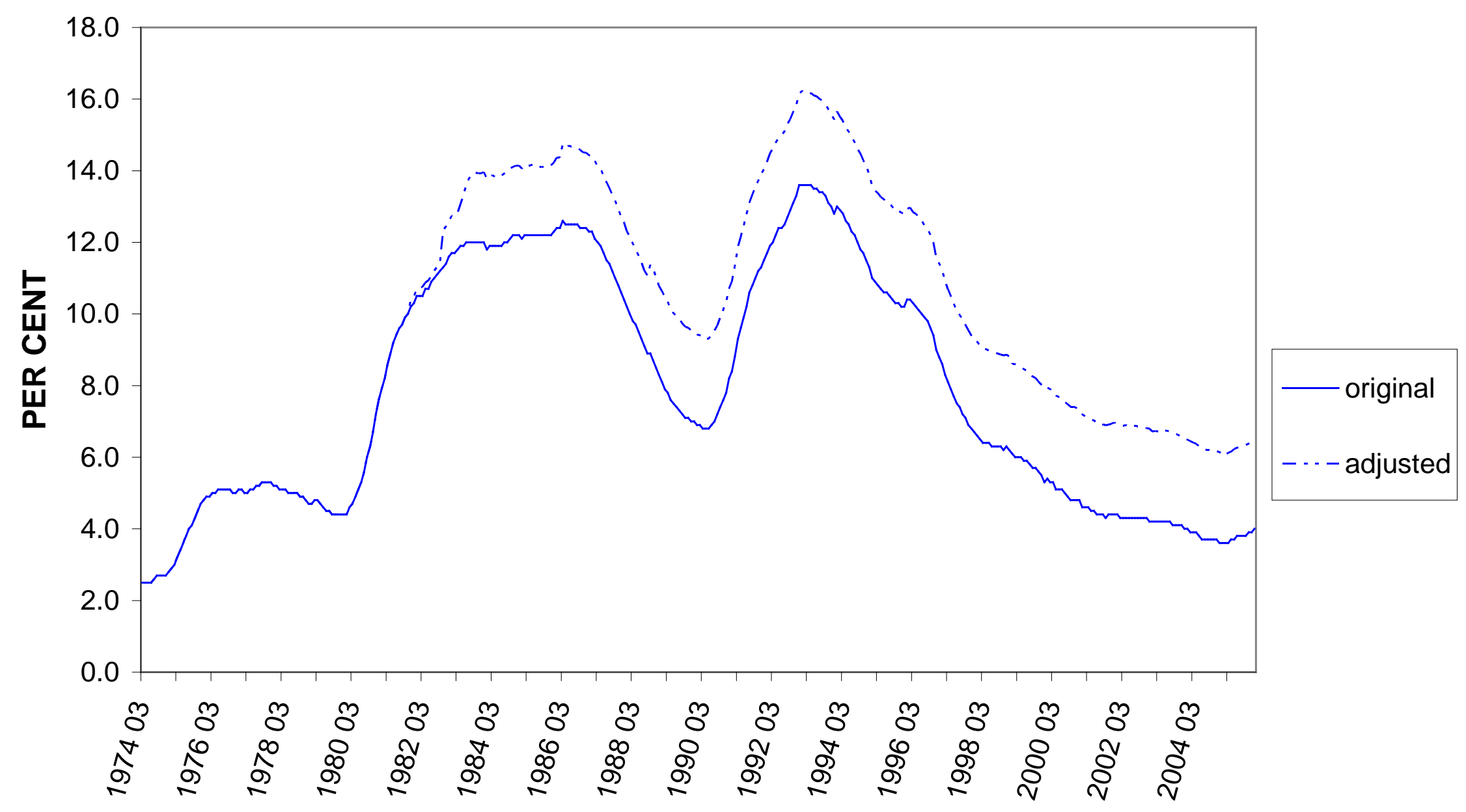


Table 2. Percentages with first birth by age 25 in NCDS and BCS70 samples by socio-economic characteristics

\begin{tabular}{|c|c|c|c|c|c|c|}
\hline Education & Low & Medium & High & & & \\
\hline NCDS & 57.7 & 32.5 & 12.3 & & & \\
\hline BCS70 & 47.4 & 31.6 & 12.3 & & & \\
\hline Age 10 or 11 ability test scores: quintiles & Lowest & Fourth & Third & Second & Highest & Missing \\
\hline NCDS & 64.7 & 56.7 & 47.5 & 40.1 & 29.9 & 48.6 \\
\hline BCS70 & 49.5 & 43.5 & 35.2 & 29.2 & 19.9 & 34.5 \\
\hline $\mathrm{CM}$ received free school meals & Yes & No & & & & \\
\hline NCDS & 65.6 & 44.9 & & & & \\
\hline BCS70 & 52.6 & 32.7 & & & & \\
\hline CM's father's social class (I = highest) & $\mathrm{V}$ & IV & III & II & 1 & Missing \\
\hline NCDS & 67.5 & 56.1 & 48.6 & 30.5 & 18.9 & 55.9 \\
\hline BCS70 & 62.1 & 40.5 & 38.5 & 23.2 & 12.8 & 38.5 \\
\hline CM's mother's age left $f / t$ education & Before 15 & 15 to 16 & 16 to 17 & 17 or more & & \\
\hline NCDS & 51.7 & 53.7 & 33.3 & 23.1 & & \\
\hline CM's mother's years of $f / t$ education & Less than ten & Ten & Eleven & Twelve plus & & \\
\hline BCS70 & 40.8 & 40.5 & 24.7 & 22.1 & & \\
\hline $\mathrm{CM}^{\prime} \mathrm{s}$ religion & None & Anglican & Catholic & Other Christian & Non-Christian & \\
\hline NCDS & 47.3 & 47.5 & 43.8 & 44.2 & 52.5 & \\
\hline BCS70 & 35.4 & 37.3 & 33.5 & 31.6 & 35.9 & \\
\hline CM number of siblings & None & One & Two & Three & Four plus & Missing \\
\hline NCDS & 37.5 & 37.8 & 48.7 & 50.6 & 59.8 & 44.7 \\
\hline BCS70 & 33.6 & 28.9 & 36.4 & 44.0 & 55.0 & 37.1 \\
\hline
\end{tabular}

Note. CM denotes cohort member 
A set of further variables to act as controls in the model was also chosen. Potential explanatory variables which are clearly endogenous, such as marital status or partnership status, were not included in the models. Variables were selected so that, as far as possible, they were similar for each cohort. Scores on ability tests taken in childhood are available at various ages for each cohort. Age 11 scores for NCDS and age 10 scores for BCS70 were used. A range of variables was selected which reflect aspects of the socio-economic background of the cohort members, such as their father's social class, mother's education level, their religion, number of siblings, and whether they experienced poverty as a child, measured by receipt of free school meals. Table 2 reports some descriptive statistics for these explanatory variables. These show the proportions having their first birth by age 25 in each cohort, broken down by each potential explanatory variable. Overall 46.6 per cent of the NCDS women and 35.1 per cent of the BCS70 women had had a first birth by age 25 .

Table 2 also shows that the percentage with a first birth by age 25 was inversely related to scores on ability tests in childhood. For the NCDS cohort, nearly two-thirds of those in the lowest quintile on the ability test scores had had at least one child by age 25 , compared with just 30 per cent for the highest quintile. For the BCS70 cohort, this percentage fell from about half of those in the lowest quintile on the test scores, to 20 per cent in the highest quintile. Women who had experienced poverty in childhood, measured by receipt of free school meals at age 10 (BCS70) or 11 (NCDS) appeared to begin childbearing at younger ages. For example, among the NCDS women who were likely to have experienced poverty in childhood, almost two-thirds had a first birth by age 25 , compared to only 45 per cent of those who had not received free school meals at age 11 . Women whose fathers were in higher socio-economic status (SES) groups and women with more educated mothers, were less likely to have had a first birth by age 25 , and this applied across both cohorts.

As for religion, those women reporting that they were Anglican and those who said they belonged to a non-Christian religion, had the highest likelihood of the birth of a first child by age 25. Generally, those cohort members who came from larger families also tended to start having children themselves at a younger age. However, for NCDS women, there was little difference between those who had no siblings compared to those who had one, while for BCS70 women, those with one sibling were somewhat less likely than those with no siblings, to have their first child by 25 .

\section{Results}

The estimated hazard models are reported in Table 3 for the NCDS cohort and in Table 4 for the BCS70 cohort. In each of these tables, model A does not control for unobserved heterogeneity, while model B is more complex and specifies nonparametric heterogeneity terms. The factor loading term in the tables refers to the unobserved heterogeneity. All models were estimated in CTM (Yi et al 1987). I estimated the models for as many transitions as were feasible. In practice, this was the first three births for each cohort. However, for the later (BCS70) cohort, only a small proportion of women had already had a third birth by their early to mid-thirties, and such women may not be very typical, so the discussion here concentrates on comparisons of the first two births.

There was a negative association between education level and the hazard of the first birth for women in the NCDS cohort and in the BCS70 cohort. The coefficients on the education variables became much larger in absolute value, once unobserved characteristics of the women were taken into account. The absolute size of the estimated education coefficients was larger for the earlier cohort. As for the hazard of second births, there was some evidence of a positive association with higher levels of education for the NCDS women, but this effect disappeared once controls for unobservable factors were incorporated into the models. There was no evidence of any statistically significant associations between education and hazards of second births among BCS70 women. Overall, since our results show later timing of the first birth for more educated women, and no evidence of faster entry to higher order births, the implication is that more educated women would have fewer children, on average, over the life course.

The unemployment rate (adjusted as described earlier to allow for changes in eligibility rules) was 
lagged by 12 months and was entered into the models as a time-varying covariate. For NCDS women, there was a negative association ('procyclical') between the lagged unemployment rate and the hazard of first births, but this was not statistically significant. There was a positive association between lagged unemployment and the hazard of second births ('anti-cyclical') and this became much larger and strongly significant after controlling for unobserved heterogeneity. Results for the third birth to NCDS women were similar. For the BCS70 women, there was also a negative association of the unemployment variable and the hazard of first births('pro-cyclical'); this was statistically significant and little affected by whether or not controls for unobservables were included in the model. The hazard of second birth was also negatively related to the lagged unemployment rate and was significant, at least in models which included controls for unobserved heterogeneity. There were, then, quite considerable differences between the two cohorts, in the relationships between the lagged unemployment rate and birth hazards, with NCDS looking like 'discouraged workers' at least for second and third births, while BCS70 look more like 'added workers' with income effects dominating substitution effects.

Table 3. Hazard models of the timing of first three births: NCDS results

\begin{tabular}{|c|c|c|c|c|c|c|}
\hline First Birth & Coeff & Std err & t-stat & Coeff & err & t-stat \\
\hline Factor Loading & & & & 8.904 & 0.788 & 11.29 \\
\hline Intercept & 0.235 & 0.093 & 2.52 & -5.310 & 0.706 & 7.52 \\
\hline Gamma_1 & 3.054 & 0.133 & 22.92 & 4.955 & 0.259 & 19.15 \\
\hline Gamma_2 & -2.012 & 0.077 & 26.09 & -1.936 & 0.117 & 16.49 \\
\hline \multicolumn{7}{|l|}{ Education (base, low) } \\
\hline Medium & -0.381 & 0.046 & 8.36 & -1.175 & 0.105 & 11.16 \\
\hline High & -0.618 & 0.059 & 10.52 & -1.999 & 0.150 & 13.34 \\
\hline $\begin{array}{l}\text { Free School Meals (FSM) at } \\
\text { age } 11\end{array}$ & 0.236 & 0.050 & 4.67 & 0.448 & 0.111 & 4.03 \\
\hline \multicolumn{7}{|l|}{ Father's SES } \\
\hline SES I & -0.222 & 0.094 & 2.37 & -0.512 & 0.180 & 2.84 \\
\hline SES II & -0.177 & 0.056 & 3.18 & -0.482 & 0.115 & 4.19 \\
\hline SES III & -0.100 & 0.040 & 2.48 & -0.228 & 0.086 & 2.64 \\
\hline SES IV & -0.052 & 0.049 & 1.05 & -0.056 & 0.107 & 0.52 \\
\hline SES data missing & -0.130 & 0.077 & 1.68 & -0.138 & 0.163 & 0.84 \\
\hline \multicolumn{7}{|c|}{ Mother's education (base, left school before age 15) } \\
\hline Mother left school aged 15 to 16 & 0.057 & 0.037 & 1.55 & 0.161 & 0.079 & 2.04 \\
\hline Mother left school aged 16 to 17 & -0.072 & 0.059 & 1.21 & -0.114 & 0.124 & 0.92 \\
\hline $\begin{array}{l}\text { Mother left school aged } 17 \text { or } \\
\text { more }\end{array}$ & -0.047 & 0.067 & 0.71 & -0.126 & 0.126 & 1.00 \\
\hline \multicolumn{7}{|c|}{ Ability Test Score Age 11 (base, lowest quintile) } \\
\hline Highest quintile & -0.256 & 0.053 & 4.85 & -0.846 & 0.118 & 7.16 \\
\hline Second quintile & -0.208 & 0.048 & 4.30 & -0.805 & 0.108 & 7.44 \\
\hline Third quintile & -0.172 & 0.048 & 3.58 & -0.709 & 0.110 & 6.42 \\
\hline Fourth quintile & -0.091 & 0.046 & 1.96 & -0.391 & 0.102 & 3.82 \\
\hline Ability test: missing data & -0.202 & 0.054 & 3.76 & -0.569 & 0.119 & 4.80 \\
\hline
\end{tabular}


(Table 3 (NCDS) cont'd)

Religion (base, no religion)

Anglican

$\begin{array}{lll}0.057 & 0.033 & 1.73\end{array}$

Roman Catholic

$\begin{array}{lll}-0.065 & 0.049 & 1.32\end{array}$

Other Christian

$\begin{array}{lll}0.035 & 0.047 & 0.74\end{array}$

Non-Christian religion

$\begin{array}{lll}0.328 & 0.161 & 2.04\end{array}$

Number of siblings (age 16, base one sibling)

No siblings

$-0.007$

$0.079 \quad 0.09$

Two siblings

$\begin{array}{lll}0.153 & 0.047 & 3.26\end{array}$

Three siblings

$\begin{array}{lll}0.112 & 0.051 & 2.19\end{array}$

Four or more siblings

$\begin{array}{lll}0.256 & 0.049 & 5.22\end{array}$

Siblings: missing data

Unemployment (lagged)

$\begin{array}{lll}0.040 & 0.048 & 0.83\end{array}$

$\begin{array}{lll}-0.012 & 0.007 & 1.67\end{array}$

Without controls for unobserved heterogeneity

Second Birth
Factor Loading
Intercept
Gamma_1
Gamma_2
Education (b
Medium
High
Free School
age 11
Father's SES
SES I
SES II
SES III
SES IV

\section{Coeff Std err t-stat}

$\begin{array}{lll}-0.485 & 0.112 & 4.32\end{array}$

$\begin{array}{lll}0.501 & 0.134 & 3.75\end{array}$

$\begin{array}{lll}-3.207 & 0.162 \quad 19.80\end{array}$

$\begin{array}{rrr}0.064 & 0.069 & 0.93 \\ -0.294 & 0.098 & 2.99 \\ 0.005 & 0.094 & 0.06 \\ 0.377 & 0.300 & 1.25\end{array}$

$\begin{array}{lll}-0.080 & 0.150 & 0.53\end{array}$

$\begin{array}{lll}0.294 & 0.095 & 3.08\end{array}$

$\begin{array}{lll}0.428 & 0.108 & 3.97\end{array}$

$\begin{array}{lll}0.672 & 0.109 & 6.14\end{array}$

$\begin{array}{lll}0.203 & 0.095 & 2.14\end{array}$

$\begin{array}{lll}-0.003 & 0.008 & 0.37\end{array}$

Including controls for unobserved heterogeneity

$\begin{array}{rrr} & \text { Std } & \\ \text { Coeff } & \text { err } & \text { t-stat } \\ 3.031 & 0.335 & 9.06 \\ -3.138 & 0.321 & 9.79 \\ 0.749 & 0.136 & 5.50 \\ -3.429 & 0.163 & 21.09 \\ & & \\ -0.108 & 0.055 & 1.96 \\ -0.059 & 0.066 & 0.89 \\ -0.098 & 0.074 & 1.34\end{array}$

SES data missing

$\begin{array}{lll}0.027 & 0.047 & 0.57 \\ 0.117 & 0.056 & 2.07\end{array}$

$\begin{array}{lll}-0.130 & 0.066 \quad 1.96\end{array}$

$\begin{array}{lll}-0.098 & 0.074 & 1.34\end{array}$

$\begin{array}{lll}0.104 & 0.094 & 1.11\end{array}$

$\begin{array}{lll}0.085 & 0.111 & 0.77\end{array}$

$\begin{array}{lll}0.048 & 0.059 & 0.81\end{array}$

$0.015 \quad 0.068$

0.22

$\begin{array}{lll}-0.019 & 0.054 & 0.35\end{array}$

$\begin{array}{lll}-0.002 & 0.048 & 0.05\end{array}$

$-0.049 \quad 0.068$

0.72

$\begin{array}{rrr}-0.049 & 0.060 & 0.81 \\ 0.052 & 0.093 & 0.56\end{array}$

0.054

0.107

0.51

Mother's education (base, left school before age 15)

Mother left school aged 15 to 16

$\begin{array}{lll}-0.015 & 0.043 & 0.35\end{array}$

$\begin{array}{lll}-0.016 & 0.049 & 0.33\end{array}$

Mother left school aged 16 to 17
Mother left school aged 17 or

$\begin{array}{lll}-0.015 & 0.065 & 0.23\end{array}$

$-0.026$

0.075

0.35

more

$\begin{array}{lll}-0.042 & 0.068 & 0.63\end{array}$

$\begin{array}{lll}-0.035 & 0.079 & 0.44\end{array}$

Ability test score age 11 (base, lowest quintile)

Highest quintile

$-0.043$

$0.062 \quad 0.70$

$\begin{array}{lll}-0.112 & 0.072 & 1.57\end{array}$

Second quintile

$-0.069$

$0.058 \quad 1.17$

$-0.136$

0.066

2.05

Third quintile

$\begin{array}{lll}-0.088 & 0.060 & 1.46\end{array}$

$-0.166$

0.069

2.42

Fourth quintile

$\begin{array}{lll}-0.059 & 0.059 & 0.99\end{array}$

$-0.097$

$0.066 \quad 1.46$

Ability test: missing data

$\begin{array}{lll}-0.010 & 0.067 & 0.16\end{array}$

$-0.060$

0.80

Religion (base, no religion)

Anglican

$\begin{array}{lll}0.111 & 0.039 & 2.87\end{array}$

$\begin{array}{lll}0.144 & 0.044 & 3.30\end{array}$

Roman Catholic

$\begin{array}{lll}0.065 & 0.056 & 1.15\end{array}$

$\begin{array}{lll}0.037 & 0.063 & 0.58\end{array}$

Other Christian

$\begin{array}{lll}0.025 & 0.053 & 0.48\end{array}$

$\begin{array}{lll}0.046 & 0.060 & 0.77\end{array}$

Non-Christian religion

$\begin{array}{lll}0.164 & 0.171 & 0.96\end{array}$

$\begin{array}{lll}0.250 & 0.194 & 1.29\end{array}$

Number of siblings (age 16, base one sibling)

No siblings

$\begin{array}{lll}-0.033 & 0.082 & 0.41\end{array}$

$\begin{array}{lll}0.002 & 0.095 & 0.02\end{array}$ 
(Table 3 (NCDS) cont'd)

Two siblings

Three siblings

Four or more siblings

Siblings: missing data

Unemployment (lagged)

$\begin{array}{rrr}0.076 & 0.051 & 1.49 \\ 0.124 & 0.059 & 2.10 \\ 0.140 & 0.057 & 2.44 \\ -0.021 & 0.054 & 0.39 \\ 0.008 & 0.005 & 1.57\end{array}$

$\begin{array}{lll}0.121 & 0.059 & 2.05 \\ 0.184 & 0.067 & 2.74 \\ 0.229 & 0.066 & 3.47 \\ 0.009 & 0.061 & 0.15 \\ 0.054 & 0.007 & 8.33\end{array}$

Without controls for

Third Birth unobserved heterogeneity

Factor Loading

Intercept

Coeff Std err t-stat

Gamma_1

Gamma_2

$\begin{array}{lll}-1.721 & 0.183 & 9.43\end{array}$

$\begin{array}{lll}-0.350 & 0.230 & 1.52\end{array}$

$\begin{array}{lll}-2.188 & 0.304 & 7.21\end{array}$

Education (base, low)

Medium

$\begin{array}{lll}-0.309 & 0.086 & 3.59\end{array}$

$\begin{array}{lll}-0.217 & 0.098 & 2.22\end{array}$

Free School Meals (FSM) at

$0.383 \quad 0.094 \quad 4.06$

age 11

Father's SES

SES I

SES II

$\begin{array}{lll}0.111 & 0.155 & 0.72\end{array}$

$\begin{array}{lll}-0.218 & 0.103 & 2.12\end{array}$

SES III

$\begin{array}{lll}-0.104 & 0.076 & 1.37\end{array}$

SES IV

$\begin{array}{lll}-0.149 & 0.094 & 1.58\end{array}$

SES data missing

$\begin{array}{lll}-0.320 & 0.154 & 2.08\end{array}$

Including controls for

unobserved heterogeneity

Mother's education (base, left school before age 15)

Mother left school aged 16 to 17

$\begin{array}{lll}0.009 & 0.071 & 0.13\end{array}$

$0.217 \quad 0.106 \quad 2.05$

Coeff Std err t-stat

$\begin{array}{lll}5.664 & 0.671 & 8.45\end{array}$

$-6.539$

$0.642 \quad 10.19$

$-0.032$

$0.234 \quad 0.14$

$-2.450$

0.306

8.02

$\begin{array}{lll}-0.454 & 0.097 & 4.66\end{array}$

$\begin{array}{lll}-0.380 & 0.110 \quad 3.44\end{array}$

Mother left school aged 17 or

more

$0.289 \quad 0.114 \quad 2.53$

0.443

$0.109 \quad 4.07$

Ability test score age 11 (base, lowest quintile)

Highest quintile

$-0.313$

$0.104 \quad 3.01$

$-0.218$

$0.093 \quad 2.34$

$-0.296$

$0.097 \quad 3.06$

Third quintile

$-0.136$

$0.091 \quad 1.50$

$-0.073$

$0.102 \quad 0.71$

0.125

$0.178 \quad 0.70$

$-0.260$

$0.118 \quad 2.20$

$-0.126$

$0.088 \quad 1.43$

$-0.166$

$0.109 \quad 1.52$

$-0.329$

$0.172 \quad 1.91$

Ability test: missing data

Religion (base, no religion)

Anglican

$\begin{array}{llllll}0.036 & 0.064 & 0.56 & 0.089 & 0.073 & 1.21\end{array}$

Roman Catholic

$0.187 \quad 0.088 \quad 2.14$

$\begin{array}{lll}0.011 & 0.081 & 0.13\end{array}$

$\begin{array}{lll}0.241 & 0.121 & 1.99\end{array}$

Other Christian

$\begin{array}{lll}0.010 & 0.090 & 0.11\end{array}$

0.227

$0.100 \quad 2.26$

$\begin{array}{lll}0.040 & 0.102 & 0.39\end{array}$

Non-Christian religion

$\begin{array}{lll}0.409 & 0.222 & 1.84\end{array}$

0.667

$0.259 \quad 2.58$

Number of siblings (age 16, base one sibling)

No siblings

$\begin{array}{lll}-0.079 & 0.152 & 0.52\end{array}$

$-0.093$

$0.167 \quad 0.56$

0.174

$0.099 \quad 1.76$

Three siblings

$\begin{array}{lll}0.165 & 0.088 & 1.89\end{array}$

0.204

$0.111 \quad 1.85$

Four or more siblings

$\begin{array}{lll}0.194 & 0.097 & 2.00\end{array}$

0.411

$0.106 \quad 3.87$

Siblings: missing data

Unemployment (lagged)

$\begin{array}{lll}0.122 & 0.090 & 1.36\end{array}$

0.115

$0.101 \quad 1.14$

$\begin{array}{lll}0.001 & 0.010 & 0.07\end{array}$

0.028

$0.011 \quad 2.62$

Log likelihood

$-10,339.32$

$9,740.96$

Note. Gamma_1 is the coefficient on the linear term and Gamma_2 on the quadratic term in the hazard specification. 
Table 4. Hazard model of the timing of first three births: BCS results

\begin{tabular}{|c|c|c|c|c|c|c|}
\hline \multirow[b]{2}{*}{ First Birth } & \multicolumn{3}{|c|}{$\begin{array}{c}\text { MODEL A } \\
\text { Without controls for } \\
\text { unobserved heterogeneity }\end{array}$} & \multicolumn{3}{|c|}{$\begin{array}{c}\text { MODEL B } \\
\text { Including controls for } \\
\text { unobserved heterogeneity }\end{array}$} \\
\hline & Coeff & Std err & t-stat & Coeff & Std err & t-stat \\
\hline Factor Loading & & & & 3.690 & 0.178 & 20.78 \\
\hline Intercept & 0.481 & 0.172 & 2.79 & -1.512 & 0.254 & 5.96 \\
\hline Gamma_1 & 2.456 & 0.150 & 16.37 & 2.367 & 0.168 & 14.11 \\
\hline Gamma_2 & -1.535 & 0.141 & 10.86 & -0.620 & 0.169 & 3.66 \\
\hline \multicolumn{7}{|l|}{ Education (base, low) } \\
\hline Medium & -0.273 & 0.040 & 6.82 & -0.442 & 0.060 & 7.39 \\
\hline High & -0.695 & 0.054 & 12.87 & -1.281 & 0.077 & 16.54 \\
\hline \multicolumn{7}{|l|}{ Free School Meals (FSM) at } \\
\hline FSM data missing & 0.153 & 0.074 & 2.07 & 0.069 & 0.107 & 0.65 \\
\hline \multicolumn{7}{|l|}{ Father's SES } \\
\hline SES I & -0.420 & 0.129 & 3.27 & -0.509 & 0.189 & 2.69 \\
\hline SES II & -0.387 & 0.097 & 3.99 & -0.495 & 0.150 & 3.31 \\
\hline SES III & -0.288 & 0.088 & 3.28 & -0.316 & 0.137 & 2.32 \\
\hline SES IV & -0.331 & 0.097 & 3.40 & -0.263 & 0.150 & 1.75 \\
\hline SES data missing & -0.314 & 0.097 & 3.25 & -0.231 & 0.151 & 1.53 \\
\hline \multicolumn{7}{|c|}{ Mother's education (base, less than $10 \mathrm{yrs} f / t$ education) } \\
\hline $10 \mathrm{yrs}$ of $\mathrm{f} / \mathrm{t}$ education & 0.081 & 0.076 & 1.07 & 0.103 & 0.108 & 0.95 \\
\hline $11 \mathrm{yrs}$ of $\mathrm{f} / \mathrm{t}$ education & -0.118 & 0.088 & 1.35 & -0.063 & 0.124 & 0.51 \\
\hline $\begin{array}{l}12 \text { or more yrs of } \mathrm{f} / \mathrm{t} \text { education } \\
\text { Mother's education data }\end{array}$ & -0.017 & 0.089 & 0.19 & -0.032 & 0.128 & 0.25 \\
\hline missing & 0.066 & 0.080 & 0.83 & 0.108 & 0.115 & 0.94 \\
\hline \multicolumn{7}{|c|}{ Ability test score age 10 (base, lowest quintile) } \\
\hline Highest quintile & -0.291 & 0.065 & 4.45 & -0.555 & 0.095 & 5.85 \\
\hline Second quintile & -0.218 & 0.059 & 3.68 & -0.520 & 0.085 & 6.11 \\
\hline Third quintile & -0.218 & 0.057 & 3.84 & -0.333 & 0.084 & 3.94 \\
\hline Fourth quintile & -0.062 & 0.054 & 1.14 & -0.154 & 0.080 & 1.91 \\
\hline Ability test: missing data & -0.242 & 0.057 & 4.27 & -0.406 & 0.082 & 4.94 \\
\hline \multicolumn{7}{|l|}{ Religion (base, no religion) } \\
\hline Anglican & 0.117 & 0.045 & 2.59 & 0.004 & 0.065 & 0.05 \\
\hline Roman Catholic & -0.040 & 0.062 & 0.64 & -0.159 & 0.088 & 1.81 \\
\hline Other Christian & 0.000 & 0.051 & 0.00 & -0.086 & 0.073 & 1.17 \\
\hline Non-Christian religion & 0.104 & 0.104 & 1.00 & 0.129 & 0.148 & 0.87 \\
\hline \multicolumn{7}{|c|}{ Number of siblings (age 16, base one sibling) } \\
\hline No siblings & 0.083 & 0.056 & 1.49 & 0.171 & 0.082 & 2.07 \\
\hline Two siblings & 0.150 & 0.053 & 2.81 & 0.210 & 0.078 & 2.70 \\
\hline Three siblings & 0.260 & 0.073 & 3.54 & 0.320 & 0.107 & 2.98 \\
\hline Four or more siblings & 0.505 & 0.085 & 5.97 & 0.612 & 0.124 & 4.93 \\
\hline Siblings: missing data & 0.077 & 0.045 & 1.71 & 0.150 & 0.065 & 2.33 \\
\hline Unemployment (lagged) & -0.043 & 0.009 & 4.59 & -0.048 & 0.009 & 5.12 \\
\hline
\end{tabular}


(Table 4 (BCS) cont'd)

$$
\begin{aligned}
& \text { Without controls for } \\
& \text { unobserved heterogeneity }
\end{aligned}
$$

\section{Second Birth}

Factor Loading

Intercept

Gamma_1

Gamma_2

Education (base, low)

Medium

High

Free School Meals (FSM) at age 10

FSM data missing

Father's SES

SES I
SES II
SES III
SES IV

SES data missing

Mother's education (base, less than 10 yrs

$10 \mathrm{yrs}$ of $\mathrm{f} / \mathrm{t}$ education

$11 \mathrm{yrs}$ of $\mathrm{f} / \mathrm{t}$ education

12 or more $y r s$ of $f / t$ education

Mother's education data missing

Ability Test Score Age 10 (base, lowest quintile)

Highest quintile

Second quintile

Third quintile

Fourth quintile

Ability test: missing data

Religion (base, no religion)

Anglican

Roman Catholic

Other Christian

Non-Christian religion

Number of Siblings (age 16, base one sibling)

No Siblings

Two siblings

Three Siblings

Four or more siblings

Siblings: missing data

Unemployment (lagged)

\section{Coeff Std err t-stat}

$\begin{array}{lll}-0.473 & 0.194 & 2.44\end{array}$

$\begin{array}{lll}2.628 & 0.228 & 11.53\end{array}$

$\begin{array}{lll}-5.994 & 0.396 & 15.13\end{array}$

$\begin{array}{lll}-0.030 & 0.051 & 0.59\end{array}$

$\begin{array}{lll}0.045 & 0.065 & 0.68\end{array}$

$\begin{array}{lll}-0.024 & 0.068 & 0.35\end{array}$

$\begin{array}{lll}0.141 & 0.098 & 1.43\end{array}$

$\begin{array}{lll}0.424 & 0.173 & 2.46\end{array}$

$\begin{array}{lll}0.290 & 0.134 & 2.16\end{array}$

$\begin{array}{lll}0.087 & 0.125 & 0.69\end{array}$

0.133

$-0.026$

0.137

0.136

0.97

0.19

$\mathrm{f} / \mathrm{t}$ education)

$\begin{array}{lll}0.099 & 0.099 & 1.00\end{array}$

0.296

0.107

0.145

0.112

0.115

0.106

2.66

0.92

1.37

0.041

$-0.066$

$-0.053$

0.081

0.075

0.50

0.88

$-0.089$

0.074

0.72

$-0.063$

$0.072 \quad 1.24$

$0.073 \quad 0.86$

$\begin{array}{lll}0.142 & 0.057 & 2.46\end{array}$

$-0.111$

0.083

0.120

$-0.211$

0.081

0.052

$-0.057$

$-0.142$

0.008
$0.080 \quad 1.39$

$0.066 \quad 1.26$

$0.128 \quad 0.94$

$0.072 \quad 2.93$

$0.065 \quad 1.24$

$0.094 \quad 0.56$

$0.119 \quad 0.48$

$0.056 \quad 2.52$

$0.007 \quad 1.04$
Including controls for unobserved eterogeneity

$\begin{array}{rlr}\text { Coeff } & \text { Std err } & \text { t-stat } \\ 3.670 & 0.456 & 8.05 \\ -2.779 & 0.438 & 6.34 \\ 3.213 & 0.245 & 13.12 \\ -6.737 & 0.409 & 16.48 \\ & & \\ -0.088 & 0.059 & 1.49 \\ -0.115 & 0.077 & 1.49 \\ 0.054 & 0.078 & 0.69 \\ 0.177 & 0.108 & 1.64 \\ & & \\ 0.398 & 0.201 & 1.99 \\ 0.287 & 0.152 & 1.89 \\ 0.069 & 0.141 & 0.49 \\ 0.109 & 0.155 & 0.70 \\ -0.048 & 0.154 & 0.31\end{array}$

$\begin{array}{lll}0.149 & 0.113 & 1.32\end{array}$

$\begin{array}{lll}0.375 & 0.128 & 2.92\end{array}$

$\begin{array}{lll}0.155 & 0.132 & 1.17\end{array}$

$\begin{array}{lll}0.184 & 0.120 & 1.53\end{array}$

$\begin{array}{lll}-0.022 & 0.096 & 0.23\end{array}$

$\begin{array}{lll}-0.162 & 0.087 & 1.87\end{array}$

$\begin{array}{lll}-0.114 & 0.085 & 1.33\end{array}$

$\begin{array}{lll}-0.144 & 0.084 & 1.72\end{array}$

$\begin{array}{lll}-0.149 & 0.084 & 1.76\end{array}$

$\begin{array}{lll}0.181 & 0.066 & 2.75\end{array}$

$\begin{array}{lll}-0.141 & 0.091 & 1.55\end{array}$

$\begin{array}{lll}0.105 & 0.076 & 1.39\end{array}$

$\begin{array}{lll}0.129 & 0.147 & 0.88\end{array}$

$\begin{array}{lll}-0.206 & 0.081 & 2.53\end{array}$

$\begin{array}{lll}0.141 & 0.077 & 1.83\end{array}$

$\begin{array}{lll}0.063 & 0.108 & 0.58\end{array}$

$\begin{array}{lll}-0.004 & 0.137 & 0.03\end{array}$

$\begin{array}{lll}-0.124 & 0.064 & 1.92\end{array}$

$\begin{array}{lll}-0.032 & 0.009 & 3.49\end{array}$ 
Table 4 (BCS) cont'd)

$$
\begin{array}{cc}
\text { Without controls for } & \text { Including controls for } \\
\text { unobserved heterogeneity } & \text { unobserved heterogeneity }
\end{array}
$$

Third Birth

Factor Loading

Intercept

Gamma_1

Gamma_2

Education (base, low)

Medium

High

Free School Meals (FSM) at age

10

FSM data missing

Father's SES

SES I

SES II

SES III

SES IV

SES data missing

Mother's education (base, less than $10 \mathrm{yrs} f / t$ education)

$10 \mathrm{yrs}$ of $\mathrm{f} / \mathrm{t}$ education

$11 \mathrm{yrs}$ of $\mathrm{f} / \mathrm{t}$ education

12 or more yrs of $f / t$ education

Mother's education data missing

Ability Test Score Age 10 (base, lowest quintile)

Highest quintile

Second quintile

Third quintile

Fourth quintile

Ability test: missing data

Religion (base, no religion)

Anglican

Roman Catholic

Other Christian

Non-Christian religion

Number of Siblings (age 16, base one sibling)

No siblings

Two siblings

Three siblings

Four or more siblings

Siblings: missing data

Unemployment (lagged)

Log likelihood

$\begin{array}{rrr}\text { Coeff } & \text { Std err } & \text { t-stat } \\ -2.328 & 0.332 & 7.00 \\ 2.233 & 0.475 & 4.70 \\ -4.230 & 0.888 & 4.76\end{array}$

$-0.024$

0.101

0.147

0.24

2.25

$0.113 \quad 3.06$

0.346

$-0.042$

0.172

0.24

0.097

0.355

0.242

0.080

0.215

0.232

0.225

0.237

0.27

0.15

0.37

0.97

0.19

$-0.332$

$-0.416$

0.157

0.197

0.212

0.170

2.11

2.11

3.12

1.69

0.167

0.174

0.147

0.96

2.40

$-0.007$

0.149

0.091

0.136

0.05

0.67

0.413

0.130

3.18

0.196

0.112

0.039

0.167

1.74

0.24

0.153

0.131

0.458

0.204

1.17

2.24

0.023

0.147

0.129

0.15

0.250

0.171

1.94

0.274

0.189

1.60

0.258

0.115

1.36

0.16

0.133

0.015

9.08

$-7214.04$

$\begin{array}{rrr}\text { Coeff } & \text { Std err } & \text { t-stat } \\ 14.115 & 1.655 & 8.53 \\ -12.377 & 1.611 & 7.68 \\ 4.844 & 0.664 & 7.29 \\ -5.943 & 1.104 & 5.38\end{array}$

$\begin{array}{lll}-0.154 & 0.158 & 0.97\end{array}$

$\begin{array}{lll}0.045 & 0.224 & 0.20\end{array}$

$\begin{array}{lll}1.058 & 0.194 & 5.46\end{array}$

$\begin{array}{lll}0.410 & 0.281 & 1.46\end{array}$

$\begin{array}{lll}-0.050 & 0.512 & 0.10\end{array}$

$\begin{array}{lll}-0.140 & 0.352 & 0.40\end{array}$

$\begin{array}{lll}-0.221 & 0.310 & 0.71\end{array}$

$\begin{array}{lll}0.203 & 0.336 & 0.60\end{array}$

$\begin{array}{lll}-0.375 & 0.346 & 1.08\end{array}$

$\begin{array}{lll}-0.181 & 0.246 & 0.74\end{array}$

$\begin{array}{lll}-0.251 & 0.310 & 0.81\end{array}$

$\begin{array}{lll}-0.696 & 0.325 & 2.14\end{array}$

$\begin{array}{lll}-0.306 & 0.269 & 1.14\end{array}$

$\begin{array}{lll}-0.202 & 0.251 & 0.80\end{array}$

$\begin{array}{lll}0.254 & 0.231 & 1.10\end{array}$

$\begin{array}{lll}-0.369 & 0.232 & 1.59\end{array}$

$\begin{array}{lll}-0.270 & 0.209 & 1.29\end{array}$

$\begin{array}{lll}0.234 & 0.202 & 1.16\end{array}$

$\begin{array}{lll}0.339 & 0.170 & 2.00\end{array}$

$\begin{array}{lll}-0.028 & 0.257 & 0.11\end{array}$

$\begin{array}{lll}0.354 & 0.199 & 1.78\end{array}$

$\begin{array}{lll}0.758 & 0.332 & 2.28\end{array}$

$\begin{array}{lll}-0.162 & 0.222 & 0.73\end{array}$

$\begin{array}{lll}0.248 & 0.203 & 1.23\end{array}$

$\begin{array}{lll}0.504 & 0.273 & 1.85\end{array}$

$\begin{array}{lll}0.474 & 0.284 & 1.67\end{array}$

$\begin{array}{lll}-0.049 & 0.173 & 0.28\end{array}$

$\begin{array}{lll}0.027 & 0.025 & 1.09\end{array}$

7055.63

Note. Gamma_1 is the coefficient on the linear term and Gamma_2 on the quadratic term in the hazard specification. 
There was a strong, positive relationship between the experience of poverty in childhood (as measured by receipt of free school meals) and the hazard of the first birth. This applied to both cohorts and regardless of whether the model specification controlled for unobserved heterogeneity. The size of estimated coefficients was similar for NCDS and BCS70 samples. There was little evidence of any relationship of childhood poverty with the hazard of the second birth for either cohort. For NCDS women, the free school meals variable was marginally significant in models which did not control for unobservables, but this effect disappeared once allowance was made for unobserved heterogeneity.

The hazard of the first birth tended to be higher for those cohort members whose fathers were in lower SES categories. This finding applied to both cohorts. As for the second birth, father's SES variables were largely non-significant, but for the younger cohort, there was some evidence of higher hazards of second births for women whose fathers were in higher SES groups. On the whole, the education level of the cohort member's own mother appeared to have little association with birth hazards. Exceptions were that the cohort member's mother's leaving school at age 15 or 16, was associated with higher hazard of first birth for NCDS, while 11 years of mother's completed schooling was associated with a higher hazard of second birth for the BCS70 cohort. Certain coefficients were statistically significant, but there was no clear pattern to these results.

Those cohort members who scored highly on general ability tests in childhood, tended to have a reduced hazard for first births. The magnitude of this association increased once controls for unobservables were included in the models, and it was larger for NCDS women than for BCS70 women. There was less evidence that hazards of the second birth were associated with the ability test scores, but for NCDS it seemed that those in the second or third quintiles of attainment tended to have a higher second birth hazard.

The models also included measures of the religion of cohort members. The hazard of first births was lower for Roman Catholics in both cohorts, and was statistically significant for the NCDS women, but not significant at the 5 per cent level for the BCS70 women. Anglicans also had an increased hazard for the second birth in both cohorts. It may also be worth noting that third birth hazards were higher for Roman Catholic and those of non-Christian religion, which was perhaps more in line with prior expectations.

NCDS and BCS70 cohort members who had a large number of siblings also had a significantly higher hazard for the first birth. The number of siblings was also positively associated with the second birth for NCDS; this finding did not apply consistently for BCS70 women, but those with no siblings had a significantly lower hazard than the base case of one sibling.

Information about the non-parametric heterogeneity distributions estimated in the models for NCDS and BCS70, appears in Table 5. The procedure here was that two of the mass points were fixed at zero and one, and other mass points and all associated probabilities were freely estimated. I began by estimating a distribution with just two mass points, and increased the number of points until two converged on the same location. The outcome of this process was different for NCDS and BCS70. In the case of the models for NCDS, a distribution with six mass points could be estimated, while for BCS70 there were just three mass points. 
Table 5. Estimated mass points and probabilities

$\begin{array}{lclc}\begin{array}{l}\text { NCDS } \\ \text { Location }\end{array} & \text { SD } & \begin{array}{l}\text { Cumulative } \\ \text { probability }\end{array} & \text { SD } \\ 0.00000 & 0.00000 & 0.13258 & 0.00989 \\ 0.46785 & 0.04192 & 0.25559 & 0.07704 \\ 0.59949 & 0.07893 & 0.39177 & 0.09280 \\ 0.74234 & 0.06201 & 0.63190 & 0.17446 \\ 0.85187 & 0.03583 & 0.89496 & 0.04325 \\ 1.00000 & 0.00000 & 1.00000 & 0.00000 \\ & & & \\ \text { BCS } & & & 0.01462 \\ 0.00000 & 0.00000 & 0.33621 & 0.01242 \\ 0.75971 & 0.02120 & 0.87491 & 0.00000 \\ 1.00000 & 0.00000 & 1.00000 & \end{array}$

Note. See Model B in each of Tables 3 and 4 for details of the estimated models

The implication, essentially, is that there were a number of different groups of women in each cohort, six in the case of NCDS and three in the case of BCS70, with differing unobserved characteristics.

\section{Conclusion}

This research is concerned with the roles of education and labour market conditions in the timing of births. On education, an important finding is that the negative relation of education to the timing of the first birth is still observed - in fact becomes stronger - when one makes allowance for unobserved heterogeneity. Can it then be concluded that education is likely to be causal? While the proper treatment of residual heterogeneity addresses potential biases in parameter estimates, it does not in itself enable the causal effect of education to be identified. The person-specific unobservable component in the model is not correlated with the covariates, so that controlling for unobserved heterogeneity will not address the endogeneity of educational attainment, if the latter is correlated with this unobservable component. However, it can plausibly be argued that the person-specific heterogeneity correlated with education has effectively been removed by the inclusion of other variables associated with educational attainments, particularly own cognitive ability, father's SES, mother's education and the number of siblings. In other words, the inclusion of a number of other variables correlated with education makes a causal interpretation more likely, as the heterogeneity remaining will not be correlated with own education. The results, then, are consistent with an interpretation which sees education as having a causal effect on fertility, rather than there just being an

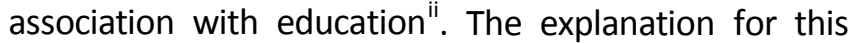
would be that, not only is childbearing avoided during studies, but once a woman is on the labour market, earnings reach higher levels than those which might be achieved if first childbearing is not delayed. Women who attain higher levels of education have higher earning potential, and therefore a larger opportunity cost in terms of lost earnings, if time is spent out of the paid labour force giving birth to, and looking after, children. The level of education may influence fertility dynamics for a number of reasons, including skills in effective use of contraception, parenting skills, and knowledge about the responsibilities involved in raising children. Determining the relative importance of such changes in behaviour suggests an agenda for further research.

There were substantial differences between the 1958 and 1970 cohorts in the relationship between fertility and labour market conditions, as measured by an aggregate, time-varying series for the unemployment 
rate. The hazard of the first birth was negatively and significantly related to the unemployment rate for the 1970 cohort, but not for the 1958 cohort, while the hazard of the second birth was positively related to the unemployment rate for the 1958 cohort, but negatively related for the 1970 cohort (and was statistically significant for both cohorts). What might account for these different results? Now, the observation period for this study covered 1974 to 2004 . Over these decades, there were a number of changes in the direction of making employment and motherhood more compatible. There were the gradual improvements in maternity leave, the introduction of paternity leave, the improvement of terms for part-time employment, and with the New Labour Government, elected in 1997, a new emphasis on public support for childcare. Although these changes do not resolve themselves neatly into monthly time series, they do add up to a secular trend, differentiating the environment in which the two cohorts faced early adulthood and the prospect of fertility. They could explain why the estimated fertility reaction of the earlier cohort to the prospect of unemployment was more dominated by substitution effects, and the later cohort, by income or 'added worker' effects, like those observed in Scandinavia.

The effects of other covariates in the models appear to be broadly similar across the two cohorts. For example, NCDS and BCS70 cohort members who had a large number of siblings also had a significantly higher hazard for the first birth. There was also a positive relationship between the experience of poverty in childhood (as measured by receipt of free school meals) and the hazard of the first birth for both cohorts. This confirms that in Britain, women from disadvantaged backgrounds tend to be more likely to make an early entry into motherhood. While the findings in this paper refer to cohorts of women born in 1958 and 1970, Hawkes (2009) shows that they also hold in a survey of more recent origin, the Millennium Cohort Study.
In demographic research, and more generally in the literature on duration analysis, there has been debate on the best way to control for heterogeneity. Heckman and co-authors have advocated a robust, nonparametric approach and this method has been utilised in some studies of fertility (although not previously for UK data). Heckman and Walker (1990) analysed data on the first three births for four cohorts of Swedish women, and actually found that unobserved heterogeneity terms were not statistically significant, concluding that "unobservables correlated across spells are not an important feature of modern Swedish fertility data". In contrast, Merrigan and St-Pierre (1998) conducted a very similar analysis (in terms of explanatory variables and modelling strategy) on Canadian birth history data, and found non-parametric heterogeneity to be important. I have also utilised Heckman and Singer's non-parametric method to control for unobservables. Controlling for heterogeneity improved the fit of the models, in that the likelihood was improved and the factor loading terms in our models were highly significant for all transitions. Moreover, controlling for unobserved heterogeneity made a considerable difference to substantive research findings. Before allowing for unobservables, it appeared that there was a positive association between education and the hazard of second birth for the NCDS cohort. Also, unemployment did not appear to be related to the timing of higher-order births. Once controls for unobservables were incorporated into the models, education was no longer significantly related to second birth hazards, while it became apparent that there was a positive association between unemployment and the hazards of second and third births for the NCDS cohort. These results affirm the importance of including robust controls for unobservables, when modelling the timing of births.

\section{Acknowledgements}

This paper is one component of a project on fertility in Britain and the US, led by Professor Heather Joshi and Professor Mark Killingsworth, and I am very grateful to them for advice and comments at all stages of the work on this paper. Helpful comments were also received from Dr Kirstine Hansen, from conference participants at ESPE (London) and EALE (Amsterdam) and from participants at an Institute of Education seminar. Funding from the ESRC UPTAP programme and from the British Academy is also gratefully acknowledged. 


\section{References}

Aassve A, Burgess S, Propper C and Dickson M. (2006) Employment, family union and childbearing decisions in Great Britain. Journal of the Royal Statistical Society, 169, 781-804.

Ahn N and Mira P. (2001) Job bust, baby bust? Evidence from Spain. Journal of Population Economics, 14, 505521.

Allison PD. (1984) Event history analysis. Sage, Beverley Hills, CA..

Blossfeld H-P, Golsch K and Rohwer G. (2007) Event history analysis with stata. Lawrence Erlbaum Associates, Mahwah, New Jersey.

Boyer GR and Hatton TJ. (2002) New estimates of British unemployment, 1870-1913. Journal of Economic History, 62, 643-675.

Bray H. (2008) National population projections 2006-based. Office for National Statistics, Basingstoke.

Crafts N. (2007) Living standards. In N Crafts, I Gazeley and A Newell. eds. Work and pay in twentieth-century Britain. Pp 11-34. Oxford University Press, Oxford.

Davies RB. (1994) From cross-sectional to longitudinal analysis. In A Dale and RB Davies. eds. Analyzing social and political change: a casebook of methods. Pp 20-40. Sage Publications, London.

del Bono E. (2001) Estimating fertility responses to expectations: evidence from the 1958 British Cohort. Discussion Paper No 80: University of Oxford, Department of Economics, Oxford.

Dex S, Gustaffson S, Jenkins A, Joshi H, Kenjoh E and Killingsworth MR. (2005) Mothers' changing labour supply in Britain, the USA and Sweden. In R Gomez-Salvador, A Lamo, B Petrongolo, M Ward and E Wasmer. eds. Labour supply and incentives to work in Europe. Pp 115-150. Edward Elgar, Cheltenham, UK.

Ermisch J and Pevalin D. (2003) Does a teen birth have a longer-term impact on the mother? Evidence from the 1970 British Cohort Study. ISER Working Paper 2003-28. ISER, University of Essex, Colchester.

Ermisch, J and Pevalin D. (2005) Early motherhood and later partnerships. Journal of Population Economics, 18, 469-489.

Gustaffson S. (2001) Optimal age at motherhood: theoretical and empirical considerations on postponement of maternity in Europe. Journal of Population Economics, 14, 225-247.

Gutierrez-Domenech M. (2002) The impact of the labour market on the timing of marriage and births in Spain. Discussion Paper 556: London School of Economics, London.

Hawkes D. (2003) Education, earnings, ability and early child bearing: evidence from a sample of UK twins. Unpublished PhD thesis. Queen Mary, University of London, London.

Hawkes D. (2009) The UK Millennium Cohort Study and the circumstances of early motherhood. In R Edwards. ed. Researching family, community and generational change. Routledge, London.

Heckman JJ and Singer B. (1984) A method for minimizing the impact of distributional assumptions in econometric models for duration data. Econometrica, 52, 271-320.

Heckman JJ and Walker JR. (1990) The relationship between wages and income and the timing and spacing of births: evidence from Swedish longitudinal data. Econometrica, 58, 1411-1441.

Hoem B. (2000) Entry into motherhood in Sweden: the influence of economic factors on the rise and fall in fertility, 1986-1997. Demographic Research, 2.

Hotz V, Klerman J and Willis R. (1997). The economics of fertility in developed countries: a survey. In M Rosenzweig and O Stark. eds. Handbook of population and family economics. Elsevier, New York.

Kiefer NM. (1988) Economic duration data and hazard functions. Journal of Economic Literature, 26, 646-679.

Killingsworth $\mathrm{M}$ and Heckman J. (1986) Female labor supply: a survey. In O Ashenfelter and R Layard. eds. Handbook of labor economics. Pp103-204. Elsevier Science Publishing Company, New York.

Kravdal O. (1992) The emergence of a positive relation between education and third birth rates in Norway with supportive evidence from the United States. Population Studies, 46, 459-475.

Kravdal, O, (2002) The impact of individual and aggregate unemployment on fertility in Norway. Demographic Research, 6, 263-294.Kreyenfeld M. (2000) Employment careers and the timing of first births in East Germany, MPIDR Working Paper 004: Max Planck Institute for Demographic Research, Rostock, Germany.

Kreyenfeld, M. (2002). Time-squeeze, partner effect or self-selection? An investigation into the positive effect of women's education on second birth risks in West Germany. Demographic Research, 7, 15-48.

Lancaster T. (1990) The econometric analysis of transition data. Cambridge University Press, Cambridge.

Makepeace G, Dolton P, Woods L, Josh, H and Galindo-Rueda F. (2003) From school to the labour market. In E Ferri, J Bynner and M Wadsworth. eds. Changing Britain, changing lives: three generations at the end of the century. Pp 29-70. Institute of Education, London. 
Merrigan P and St-Pierre Y. (1998) An econometric and neoclassical analysis of the timing and spacing of births in Canada from 1950 to 1990. Journal of Population Economics, 11, 29-51.

Newman JL and McCulloch CE. (1984) A hazard rate approach to the timing of births. Econometrica, 52, 939-961. Office for National Statisics. (2007) Birth Statistics, Series FM1 no. 35, Table 10.3

Rendall M and Smallwood S. (2003) Higher qualifications, first-birth timing and further childbearing in England and Wales. Population Trends, 111, 18-26.

Santow $\mathrm{G}$ and Bracher M. (2001) Deferment of the first birth and fluctuating fertility in Sweden. European Journal of Population, 17, 343-363.

Wright RE, Ermisch JF, Hinde PR and Joshi HE. (1988) The third birth in Great Britain. Journal of Biosocial Science, 20, 489-496.

Yi K-M, Honore B and Walker J. (1987) CTM user's manual: ERC/NORC and University of Chicago, Chicago. 


\section{Appendix 1. Policy milestones affecting mothers' employment in the UK since 1974}

\begin{tabular}{|c|c|c|}
\hline $\begin{array}{l}\text { Date of } \\
\text { implementation }\end{array}$ & Legislation & Statutory provisions \\
\hline 1975 & Child Benefit Act 1975 & Universal cash benefit paid to mothers \\
\hline December 1975 & Equal Pay Act 1970 & Equal pay for equal work \\
\hline June 1976 & $\begin{array}{l}\text { Employment } \\
\text { Protection Act } 1975\end{array}$ & $\begin{array}{l}\text { Right to reinstatement up to } 29 \text { weeks after birth for those } \\
\text { who qualified (fulltime for } 119 \text { weeks with same employer } \\
\text { or } 265 \text { weeks part-time) }\end{array}$ \\
\hline April 1977 & $\begin{array}{l}\text { Employment } \\
\text { Protection Act } 1975\end{array}$ & $\begin{array}{l}\text { Statutory maternity pay replaced lower flat rate benefit (s.t. } \\
\text { qualification conditions), } 6 \text { weeks at a rate related to } \\
\text { earnings, flat rate allowance still available } 12-14 \text { weeks }\end{array}$ \\
\hline 1983 & $\begin{array}{l}\text { Equal Pay Amendment } \\
\text { Act }\end{array}$ & Equal pay for work of equal value \\
\hline \multirow[t]{2}{*}{1992} & $\begin{array}{l}\text { Social Security } \\
\text { Contributions and } \\
\text { Benefits Act } 1992 \\
\end{array}$ & Updated conditions for payment of statutory maternity pay \\
\hline & $\begin{array}{l}\text { Workplace ( Health and } \\
\text { Safety) Regulations } \\
1992\end{array}$ & $\begin{array}{l}\text { Employers required to provide for pregnant women to rest } \\
\text { and breastfeeding women to express breastmilk at work }\end{array}$ \\
\hline April 1990 & Finance Act & $\begin{array}{l}\text { Introduction of independent taxation for husbands and } \\
\text { wives }\end{array}$ \\
\hline October 1994 & $\begin{array}{l}\text { EU Directive } 1992 \\
\text { Trade Union Reform } \\
\text { and Employment } \\
\text { Rights Act } 1993\end{array}$ & $\begin{array}{l}\text { Relaxed conditions of eligibility for leave - a response to EU } \\
\text { Directive on Part-time Workers }\end{array}$ \\
\hline \multirow[t]{3}{*}{1998} & $\begin{array}{l}\text { National Minimum } \\
\text { wage } 1998\end{array}$ & Affects women (part-timers) disproportionately \\
\hline & $\begin{array}{l}\text { Working time } \\
\text { Regulation } 1998\end{array}$ & $\begin{array}{l}\text { Regulates the work week, annual leave, rest periods and } \\
\text { night work }\end{array}$ \\
\hline & $\begin{array}{l}\text { National Child Care } \\
\text { Strategy }\end{array}$ & Began a rollout of subsidized places for pre-school children \\
\hline June 1999 & $\begin{array}{l}\text { Employment Relations } \\
\text { Act } 1999\end{array}$ & $\begin{array}{l}\text { Further improvement of rights to leave. Introduction of } \\
\text { unpaid parental leave and leave for family emergences } \\
\text {-a response to EU directive on parental leave }\end{array}$ \\
\hline July 2000 & $\begin{array}{l}\text { The Part time Workers } \\
\text { (Prevention of Less } \\
\text { Favourable Treatment } \\
\text { Regulations) } 2000\end{array}$ & $\begin{array}{l}\text { Part-timers should not be treated less favourably in their } \\
\text { contractual terms and conditions than comparable full- } \\
\text { timers, }\end{array}$ \\
\hline April 2003 & $\begin{array}{l}\text { Maternity and Parental } \\
\text { Leave Regulations } \\
\text { 1999, Amendments } \\
2002 \\
\text { Employment Act } 2002\end{array}$ & $\begin{array}{l}\text { Paid leave increased to } 26 \text { weeks. Paid paternity leave ( } 2 \\
\text { weeks) introduced, also adoption leave. Employers obliged } \\
\text { to consider requests for flexible working }\end{array}$ \\
\hline October 2008 & $\begin{array}{l}\text { Work and Family Act } \\
2006\end{array}$ & Further increased in maternity leave to 52 weeks \\
\hline
\end{tabular}


The above table sets out some of the main milestones in policies which affected the compatibility of paid work and motherhood for the two cohorts investigated in this paper.

It focuses particularly on maternity provisions, where statutory benefits are shown. Some mothers would have been entitled to better leave or pay than the statutory, which was offered by some employers, sometimes in response to negotiation by some trades unions. Many others, especially in the period before the mid-1990s, would not have met conditions of service with their employer to be eligible even for statutory benefits. Before the mid-1970s there were flat-rate maternity benefits for women contributing to National Insurance, and a means-tested allowance for those not insured. This reflected the assumption made by the principal architect of Britain's post-war welfare state, Sir William Beveridge, that mothers would not generally return to the labour market after childbirth.

Note also that the table does not include all the relevant legislation. For example, there was a tightening of qualifying conditions in the $1980 \mathrm{~s}$ to protect small employers, and nor is every detailed change in levels, duration and eligibility for the two strands of statutory paid leave included. Also omitted is the introduction of Working Tax Credits under New Labour and a number of details of public support for child care.

Main source: Earnshaw J. (1999) Maternity rights in the UK : light at the end of the tunnel? Economic and Labour Relations Review 10, 196-187.

\section{Endnotes}

${ }^{i}$ In some disciplines unobserved heterogeneity may be referred to as unmeasured confounding.

ii Controlling robustly for heterogeneity allows us to be much more confident that education is having an effect on fertility behaviour. However, it is possible to think of circumstances in which such results would be consistent with education not being causally linked to fertility; for example, if there are unanticipated shocks which impact on education and hence on fertility. 